RESEARCH REPORT

\title{
Psychosocial factors and work related sickness absence among permanent and non-permanent employees
}

\author{
David Gimeno, Fernando G Benavides, Benjamin C Amick III, Joan Benach, José Miguel Martínez
}

J Epidemiol Community Health 2004;58:870-876. doi: 10.1136/jech.2003.016634

See end of article for authors' affiliations

....................

Correspondence to: Dr D Gimeno,

Occupational Health Research Unit, Department of Experimental Sciences and Health, Universitat Pompeu Fabra, $\mathrm{C} / \mathrm{Dr}$. Aiguader 80, 08003 Barcelona, Catalonia, Spain; david.gimeno@ upf.edu

Accepted for publication 23 February 2004

\begin{abstract}
Study objective: To examine the association between psychosocial work factors and work related sickness absence among permanent and non-permanent employees by sex.

Design: A cross sectional survey conducted in 2000 of a representative sample of the European Union total active population, aged 15 years and older. The independent variables were psychological job demands and job control as measures of psychosocial work environment, and work related sickness absence as the main outcome. Poisson regression models were used to compute sickness absence days' rate ratios.

Setting: 15 countries of the European Union.

Participants: A sample of permanent $(n=12875)$ and non-permanent $(n=1203)$ workers from the Third European Survey on Working Conditions.

Results: High psychological job demands, low job control, and high strain and passive work were associated with higher work related sickness absence. The risks were more pronounced in non-permanent compared with permanent employees and men compared with women.

Conclusions: This work extends previous research on employment contracts and sickness absence, suggesting different effects depending on psychosocial working conditions and sex.
\end{abstract}

S ickness absence, which measures the working population's wellbeing ${ }^{12}$ and contributes to lost productivity, ${ }^{3}$ has emerged as an important public health surveillance indicator. Many studies have examined the relation between psychosocial work conditions and sickness absence. ${ }^{4-17}$ Some have found that sickness absence is related to high demands, ${ }^{45}$ low control, ${ }^{4-11}$ or their combination, ${ }^{412-14}$ while other studies have found no relation. ${ }^{15-17}$ Furthermore, failing to clarify whether sickness absence is work related or not, has research and prevention implications. ${ }^{18-20}$

In the past decade, new forms of employment contracts, especially for non-permanent employees, have emerged as a significant change in the European Union (EU) labour market compared with more standard forms of production. ${ }^{21}$ Differences in working conditions and health indicators between permanent and non-permanent employment have been reported recently. Non-permanent employees work in more hazardous psychosocial and ergonomic work environments ${ }^{22}{ }^{23}$ and experience higher mortality, ${ }^{24}$ but tend to report better health and less sickness absence than permanent employees. ${ }^{23}$ 25-27 However, most sickness absence studies use stable working populations and whether the association between psychosocial factors and sickness absence applies to non-permanent employees is unclear. In addition, women tend to have more sickness absence than men, ${ }^{28}$ and some differences in the relation between psychosocial work environment and sickness absence by sex have been found. ${ }^{6}{ }^{8}$ As far as we know, no studies have analysed the association of psychosocial work factors with sickness absence for permanent and non-permanent employees, for both sexes.

We hypothesised that psychosocial work factors (that is, high psychological demands, low control, and their combination) increase work related sickness absence risk. Furthermore, we hypothesised: (1) that sickness absence risk for psychosocial work factors would be higher for permanent than non-permanent employees; and, (2) women to be at higher risk than men. The objectives of this study were: firstly, determine whether there is a relation between psychosocial work factors and work related sickness absence; secondly, assess whether patterns differ between permanent and non-permanent employees by sex.

\section{METHODS}

\section{Participants and study sample}

Data were drawn from the Third European Survey on Working Conditions (ESWC). ${ }^{29}$ The sample design was a multi-stage random sample conducted on representative national samples of total active populations in EU member countries. The goal was to obtain 1500 employed persons per country (except 500 for Luxembourg). Employed was defined as people aged 15 years and older, having any paid job during the reference week, or who had a job but was temporarily absent. A total of 21703 interviews were conducted at workers' homes between March and April 2000, with response rates ranging from $39 \%$ in Italy to $76 \%$ in Germany. ${ }^{29}$

Participants were asked about their employment status (employed or self employed), and contract (permanent or non-permanent, which included fixed term and temporary agency contracts). Among those employed, only permanent and non-permanent employees were selected for the analyses $\left(\mathrm{n}=17\right.$ 910). More details are given elsewhere. ${ }^{29}$ Employees with incomplete data $(\mathrm{n}=1858)$ were excluded. For a stable psychosocial work environment estimate, only employees with at least one year in their job were selected. The final sample $(n=14078)$ included 12875 permanent and 1203 non-permanent employees.

\section{Work related sickness absence}

Work related sickness absence was defined using two questions: In your main job, over the past 12 months, how many days were you absent because of... "an accident at work" or "health problems caused by your work". The analysis was based on 13957 employees after excluding nonanswering subjects $(\mathrm{n}=119)$ or those reporting incongruent figures (that is, more than 365 days absent per year) $(n=2)$. 


\begin{tabular}{|c|c|c|c|c|c|c|c|c|}
\hline \multirow[b]{3}{*}{ Variables } & \multicolumn{4}{|l|}{ Permanent } & \multicolumn{4}{|c|}{ Non-permanent } \\
\hline & \multirow[b]{2}{*}{ Person years } & \multicolumn{3}{|c|}{$\begin{array}{l}\text { Work related sickness } \\
\text { absence }\end{array}$} & \multirow[b]{2}{*}{ Person years } & \multicolumn{3}{|c|}{$\begin{array}{l}\text { Work related sickness } \\
\text { absence }\end{array}$} \\
\hline & & Number & $\%$ & Rate $^{*}$ & & Number & $\%$ & Rate* $^{*}$ \\
\hline \multicolumn{8}{|c|}{ Psychological job demands } & 335 \\
\hline Low & 3243 & 421 & 13 & 318 & 270 & 35 & 13 & 277 \\
\hline \multirow{2}{*}{\multicolumn{9}{|c|}{ Job control }} \\
\hline & & & & & & & & \\
\hline High & 3727 & 528 & 14 & 324 & 242 & 26 & 11 & 102 \\
\hline Low & 3132 & 662 & 21 & 555 & 309 & 65 & 21 & 517 \\
\hline \multicolumn{9}{|l|}{ Job strain } \\
\hline Low strain & 1812 & 209 & 11 & 279 & 123 & 14 & 11 & 120 \\
\hline Passive & 1427 & 212 & 15 & 368 & 147 & 21 & 14 & 408 \\
\hline Active & 1904 & 316 & 16 & 366 & 120 & 12 & 10 & 84 \\
\hline High strain & 1688 & 446 & 26 & 714 & 158 & 44 & 27 & 628 \\
\hline Women & 5749 & 848 & 15 & 377 & 632 & 87 & 14 & 319 \\
\hline \multicolumn{9}{|c|}{ Psychological job demands } \\
\hline Low & 2873 & 297 & 10 & 273 & 352 & 32 & 9 & 206 \\
\hline High & 2854 & 542 & 19 & 484 & 277 & 55 & 20 & 466 \\
\hline \multicolumn{9}{|l|}{ Job control } \\
\hline High & 2983 & 363 & 12 & 277 & 242 & 29 & 12 & 212 \\
\hline Low & 2758 & 485 & 17 & 486 & 391 & 58 & 15 & 385 \\
\hline \multicolumn{9}{|l|}{ Job strain } \\
\hline Low strain & 1546 & 143 & 9 & 225 & 132 & 11 & 8 & 232 \\
\hline Passive & 1322 & 154 & 12 & 331 & 220 & 21 & 9 & 190 \\
\hline Active & 1423 & 216 & 15 & 336 & 108 & 18 & 17 & 189 \\
\hline High strain & 1431 & 326 & 23 & 631 & 169 & 37 & 21 & 644 \\
\hline Total & 12619 & 2040 & 16 & 406 & 1183 & 178 & 15 & 326 \\
\hline
\end{tabular}

Annual absence days rates, expressed per 100 person years, were computed by dividing the total absence days number during the past year by the working days at risk for each person. ${ }^{8}$ We calculated the number of days worked by subtracting absence days due to work from total possible working days, considering a working year of 365 days. Absence days was assumed to be a countable variable that can take values $0,1,2, \ldots$ without a determined limit, so we considered the absence days number, for each subject, followed a Poisson distribution.

\section{Psychosocial work risk factors}

The Karasek's job strain model guided psychosocial exposure measurement. ${ }^{4}$ Psychological job demands were measured by three questions. Two asked the frequency ( $1-7$ options) the employee's main job entailed working "at very high speed" and "to tight deadlines". Options "almost never" or "never" were assigned a 0, and any other responses ("all the time", "almost all of the time", "around three quarters of the time", "around half of the time", or "around a quarter of the time") were assigned 1 . The third question asked whether participants "have enough time to get the job done". A "yes" was given a 0 and "no" 1 .

Job control was assessed by 11 items measuring whether the employee's main job entailed "solving unforeseen problems on your own", "learning new things" or "monotonous tasks", the possibility to "influence your working hours", "take a break when you wish", "decide when to take holidays or days off", discuss the "working conditions in general" or the "work organisation when changes take place", change the "tasks order", the "work methods", or the "speed or rate of work". A "yes" to the "monotonous tasks" item and a "no" to all remaining items were assigned 1 .

Subjects were assigned the mean of the total sum of the item scores for each scale based on the items they had answered. It was required that more than half of the items were endorsed (that is, two for demands and six for control) for the respondent to be assigned a score, otherwise the scale was set to missing. Cronbach's $\alpha$ was 0.53 for job demands and 0.75 for job control.

Following standard procedures, both psychosocial factors were dichotomised on the median, with values equal to the median classified in the low exposure category (low demands or high control). ${ }^{30}$ Both psychosocial factors were combined to create four work states: high strain (high demands and low control), active work (high demands and high control), passive work (low demands and low control), and low strain (low demands and high control). In multivariate analyses, low strain was the reference group.

\section{Covariates}

Covariates included sociodemographic variables: age, household chores, children living at home, marital status, and country; physical work conditions: noise too loud, vibrations, breathing in vapours or fumes, extreme temperatures and carrying heavy loads; and, employment related variables: company size and economic sector.

\section{Statistical analysis}

Crude and adjusted rate ratios (RR) and their 95\% confidence intervals $(95 \% \mathrm{CI})$ were calculated. The use of Poisson models assumes the mean is equal to the variance, but frequently the mean differs from the variance causing underestimation of the standard error. A marginal approach based on quasilikelihood estimation methods ${ }^{31}$ was used to account for problems with variance over dispersion and to reduce the risk of committing a type I error. Interaction between psychosocial factors and employment status was assessed by creating a multiplicative term and testing the term's significance. ${ }^{32} 33$ All analyses were performed using Stata/SE version 8.2 (StataCorp, College Station, TX). 
Table 2 Distribution of sickness absence by sociodemographic variables, occupational factors, economic sector, and country in a sample of workers $(n=13957)$ from the Third European Survey on Working Conditions (2000)

\begin{tabular}{|c|c|c|c|c|c|c|c|c|c|c|c|c|}
\hline \multirow[b]{3}{*}{ Variables } & \multicolumn{6}{|c|}{ Permanent } & \multicolumn{6}{|c|}{ Non-permanent } \\
\hline & \multicolumn{3}{|l|}{ Men } & \multicolumn{3}{|l|}{ Women } & \multicolumn{3}{|l|}{ Men } & \multicolumn{3}{|l|}{ Women } \\
\hline & Number & $\%$ & Rate* $^{*}$ & Number & $\%$ & Rate $^{*}$ & Number & $\%$ & Rate $^{*}$ & Number & $\%$ & Rate* $^{*}$ \\
\hline \multicolumn{13}{|l|}{ Sociodemographic variables } \\
\hline Age (y) $(15-24)$ & 84 & 17 & 357 & 70 & 17 & 355 & 21 & 16 & 200 & 12 & 9 & 130 \\
\hline $25-34$ & 305 & 16 & 351 & 209 & 13 & 322 & 28 & 14 & 261 & 34 & 15 & 422 \\
\hline $35-44$ & 399 & 18 & 491 & 282 & 15 & 386 & 23 & 20 & 355 & 23 & 14 & 351 \\
\hline $45-54$ & 298 & 17 & 456 & 216 & 15 & 404 & 13 & 19 & 669 & 13 & 14 & 262 \\
\hline $55+$ & 106 & 16 & 432 & 71 & 15 & 454 & 6 & 13 & 509 & 5 & 13 & 367 \\
\hline Household chores (Yes) & 374 & 20 & 494 & 739 & 15 & 375 & 32 & 19 & 429 & 71 & 15 & 302 \\
\hline Marital status (Living alone) & 349 & 18 & 422 & 281 & 16 & 339 & 41 & 16 & 377 & 33 & 12 & 307 \\
\hline $\begin{array}{l}\text { Children at home (Yes) } \\
\text { Occupational risk factors }\end{array}$ & 513 & 17 & 451 & 377 & 14 & 344 & 32 & 17 & 368 & 39 & 14 & 324 \\
\hline Noise too loud (Yes) & 628 & 24 & 591 & 264 & 24 & 625 & 51 & 24 & 578 & 35 & 23 & Occupational risk factors \\
\hline Vibrations (Yes) & 513 & 24 & 599 & 131 & 24 & 619 & 43 & 24 & 609 & 15 & 20 & $\begin{array}{l}440 \\
318\end{array}$ \\
\hline Vapours and fumes (Yes) & 527 & 26 & 697 & 185 & 23 & 680 & 41 & 25 & 534 & 14 & 15 & 253 \\
\hline Extreme temperatures (Yes) & 286 & 29 & 736 & 92 & 29 & 969 & 29 & 29 & 820 & 6 & 18 & 131 \\
\hline Loads (Yes) & 659 & 25 & 692 & 366 & 22 & 620 & 59 & 23 & 574 & 52 & 25 & 582 \\
\hline Company size (1-9 workers) & 241 & 16 & 366 & 207 & 12 & 300 & 34 & 19 & 215 & 23 & 10 & 194 \\
\hline 10-499 workers & 735 & 17 & 441 & 524 & 16 & 392 & 46 & 16 & 332 & 55 & 16 & 351 \\
\hline $500+$ workers & 191 & 19 & 498 & 94 & 17 & 513 & 6 & 9 & 581 & 5 & 14 & 694 \\
\hline \multicolumn{13}{|l|}{ Economic sector (NACE)† } \\
\hline $\begin{array}{l}\text { Agriculture, hunting, forestry, } \\
\text { and fishing }\end{array}$ & 25 & 19 & 278 & 8 & 17 & 242 & 2 & 15 & 167 & 3 & 18 & 495 \\
\hline \multicolumn{13}{|l|}{ Mining, quarrying, and } \\
\hline manufacturing & 338 & 19 & 476 & 122 & 16 & 328 & 10 & 11 & 330 & 7 & 13 & 499 \\
\hline \multicolumn{13}{|l|}{ Electricity, gas, and water } \\
\hline supply & 12 & 11 & 254 & 4 & 22 & 1123 & 2 & 25 & 252 & - & - & - \\
\hline Construction & 178 & 24 & 647 & 6 & 7 & 69 & 28 & 32 & 601 & - & - & - \\
\hline \multicolumn{13}{|l|}{ Wholesales and retail trade, } \\
\hline & 111 & 13 & 367 & 105 & 11 & 316 & 11 & 16 & 277 & 13 & 15 & 366 \\
\hline Hotels and restaurants & 27 & 15 & 304 & 52 & 20 & 372 & 1 & 3 & 27 & 4 & 10 & 54 \\
\hline \multicolumn{13}{|l|}{ Transportation and } \\
\hline communication & 141 & 19 & 465 & 44 & 20 & 762 & 6 & 15 & 78 & 4 & 22 & 662 \\
\hline Financial intermediation & 30 & 12 & 217 & 24 & 10 & 156 & - & - & - & 1 & 7 & 72 \\
\hline Real state and business & 57 & 13 & 348 & 43 & 13 & 389 & 2 & 6 & 24 & 6 & 14 & 137 \\
\hline Public administration & 108 & 16 & 385 & 59 & 13 & 336 & 6 & 13 & 236 & 5 & 12 & 557 \\
\hline Other services & 158 & 17 & 364 & 373 & 15 & 424 & 21 & 16 & 384 & 44 & 14 & 300 \\
\hline \multicolumn{13}{|l|}{ Country } \\
\hline Belgium & 85 & 15 & 505 & 64 & 17 & 445 & 7 & 22 & 379 & 4 & 14 & 799 \\
\hline Denmark & 63 & 12 & 234 & 63 & 12 & 258 & 9 & 26 & 282 & 4 & 12 & 148 \\
\hline Germany & 133 & 23 & 443 & 74 & 16 & 271 & 5 & 16 & 154 & 9 & 26 & 445 \\
\hline Greece & 19 & 8 & 79 & 6 & 4 & 248 & 6 & 23 & 674 & 1 & 5 & 10 \\
\hline Italy & 64 & 12 & 210 & 24 & 7 & 156 & 2 & 7 & 86 & 2 & 5 & 426 \\
\hline Spain & 75 & 15 & 359 & 20 & 10 & 177 & 16 & 17 & 403 & 8 & 12 & 156 \\
\hline France & 98 & 18 & 578 & 65 & 15 & 386 & 9 & 16 & 323 & 5 & 10 & 290 \\
\hline Ireland & 51 & 11 & 195 & 35 & 9 & 138 & 1 & 3 & 11 & 3 & 6 & 110 \\
\hline Luxembourg & 62 & 25 & 754 & 21 & 15 & 307 & 3 & 38 & 115 & - & - & - \\
\hline Netherlands & 121 & 23 & 651 & 107 & 22 & 885 & 6 & 29 & 2031 & 4 & 11 & 583 \\
\hline Portugal & 56 & 14 & 545 & 45 & 11 & 357 & 4 & 11 & 95 & 7 & 10 & 422 \\
\hline United Kingdom & 67 & 15 & 245 & 41 & 10 & 203 & 6 & 11 & 216 & 4 & 10 & 67 \\
\hline Finland & 100 & 25 & 629 & 117 & 28 & 636 & 8 & 23 & 349 & 14 & 20 & 328 \\
\hline Sweden & 90 & 18 & 529 & 103 & 19 & 599 & 5 & 19 & 151 & 18 & 34 & 354 \\
\hline Austria & 108 & 21 & 484 & 63 & 12 & 256 & 4 & 13 & 302 & 4 & 11 & 524 \\
\hline
\end{tabular}

\section{RESULTS}

Permanent ( $17 \%$ in men, $15 \%$ in women) and nonpermanent employees (16\% in men, $14 \%$ in women) showed similar sickness absence percentages (table 1). Employees exposed to high demands or low control showed higher sickness absence days' rates compared with low demands or high control, respectively. Overall, sickness absence days' rates were slightly higher in permanent than in nonpermanent employees, and in men as compared with women. High strain work showed the highest percentages (around $21 \%-27 \%)$, while the lowest were found in low strain (around $8 \%-11 \%$ ). Also, high strain had the highest rates (that is, in men, 628 days in non-permanent, and 714 days in permanent), followed by passive work (that is, in men, 368 days in permanent, 408 days in non-permanent).
There were small differences in sickness absence days' rates and percentages between types of employment by age (table 2). Permanent employees showed slightly higher sickness absence figures regarding household chores, living alone, and with children at home than non-permanent. Both types of employees reported similar exposures to physical working conditions. Sickness absence increased with company size, although in non-permanent employees the opposite was found for sickness absence percentages. Construction, transport and communication, mining and quarrying, electricity, gas and water supply were sectors with high sickness absence. By country, permanent employee sickness absence percentage ranged from $4 \%$ in Greek women and $8 \%$ in Greek men to $28 \%$ in Finnish women to $25 \%$ in Finnish men. Greater variability was found in 
Table 3 Risk of work related sickness absence by psychosocial work factors for permanent and non-permanent employees and gender in a sample of workers $(n=13957)$ from the Third European Survey on Working Conditions (2000)

\begin{tabular}{|c|c|c|c|c|c|c|c|c|}
\hline \multirow[b]{2}{*}{ Variables } & \multicolumn{4}{|c|}{ Permanent } & \multicolumn{4}{|c|}{ Non-permanent } \\
\hline & $\mathrm{RRc}^{*}$ & $95 \% \mathrm{Cl}$ & RRa† & $95 \% \mathrm{Cl}$ & $\mathrm{RRc}^{*}$ & $95 \% \mathrm{Cl}$ & RRa† & $95 \% \mathrm{Cl}$ \\
\hline \multicolumn{9}{|c|}{ Men } \\
\hline \multicolumn{9}{|c|}{ Psychological job demands $\ddagger$} \\
\hline Low & 1 & & 1 & & 1 & & 1 & \\
\hline High & 1.70 & (1.50 to 1.92$)$ & 1.29 & (1.14 to 1.47$)$ & 1.42 & $(0.94$ to 2.14$)$ & 0.80 & $(0.54$ to 1.20$)$ \\
\hline \multicolumn{9}{|l|}{ Job controls } \\
\hline High & 1 & & 1 & & & & 1 & \\
\hline Low & 1.64 & $(1.46$ to 1.84$)$ & 1.45 & $(1.28$ to 1.63$)$ & 5.05 & (2.87 to 8.89$)$ & 5.05 & (3.05 to 8.35$)$ \\
\hline \multicolumn{9}{|l|}{ Job strain } \\
\hline Low strain & 1 & & 1 & & 1 & & 1 & \\
\hline Passive & 1.23 & (1.01 to 1.49$)$ & 1.24 & $(1.02$ to 1.50$)$ & 3.40 & (1.59 to 7.29$)$ & 5.20 & (2.68 to 10.07$)$ \\
\hline Active & 1.31 & (1.10 to 1.57 ) & 1.14 & $(0.95$ to 1.36$)$ & 0.70 & (0.24 to 2.05 ) & 0.85 & $(0.36$ to 2.00$)$ \\
\hline High strain & 2.48 & (2.11 to 2.92 ) & 1.80 & (1.51 to 2.13 ) & 5.24 & (2.52 to 10.89 ) & 4.11 & (2.14 to 7.89 ) \\
\hline \multicolumn{9}{|c|}{ Women } \\
\hline \multicolumn{9}{|c|}{ Psychological job demands $\ddagger$} \\
\hline Low & 1 & & 1 & & 1 & & 1 & \\
\hline High & 1.71 & $(1.50$ to 1.95$)$ & 1.17 & (1.02 to 1.34$)$ & 2.26 & $(1.50$ to 3.41$)$ & 2.12 & (1.35 to 3.32 ) \\
\hline \multicolumn{9}{|l|}{ Job controls } \\
\hline High & 1 & & 1 & & 1 & & 1 & \\
\hline Low & 1.82 & (1.59 to 2.07$)$ & 1.92 & $(1.68$ to 2.20$)$ & 1.82 & $(1.15$ to 2.86$)$ & 2.09 & $(1.33$ to 3.28$)$ \\
\hline \multicolumn{9}{|l|}{ Job strain } \\
\hline Low strain & 1 & & 1 & & 1 & & 1 & \\
\hline Passive & 1.64 & $(1.33$ to 2.03$)$ & 1.86 & $(1.51$ to 2.30$)$ & 0.82 & $(0.42$ to 1.58$)$ & 0.89 & $(0.46$ to 1.71$)$ \\
\hline Active & 1.54 & (1.25 to 1.90 ) & 1.13 & $(0.92$ to 1.40$)$ & 0.81 & $(0.37$ to 1.79$)$ & 0.72 & $(0.33$ to 1.59$)$ \\
\hline High strain & 2.88 & $(2.38,3.47)$ & 2.22 & (1.84 to 2.70 ) & 2.77 & (1.58 to 4.87 ) & 2.98 & (1.66 to 5.38 ) \\
\hline
\end{tabular}

${ }^{*}$ Crude rate ratio; tadjusted rate ratio for age, marital status, children at home, household chores, country, economic sector, company size, vibrations, fumes, noise, extreme temperatures, carrying load; $¥ 2+$ job control; $\$ 2+$ job demands.

non-permanent employees $(5 \%$ in Italian women to $34 \%$ in Swedish women and $3 \%$ in Irish men to $38 \%$ in Luxembourgian men).

After adjustment, employees with high demands (that is, for permanent, $R R=1.29$ in men, $R R=1.17$ in women) or low control (that is, for permanent, $\mathrm{RR}=1.45$ in men, $\mathrm{RR}=1.92$ in women) had higher risk of sickness absence than those with low demands or high control, respectively (table 3). This association was stronger in non-permanent than in permanent employees. For instance, male permanent employees with low job control had a $\mathrm{RR}=1.45$ while nonpermanent had a four times higher risk $(R R=5.05)$. In women, high demands in permanent employees showed a $\mathrm{RR}=1.17$ while it was 2.12 in non-permanent. Compared with low-strain work, high strain had a significantly greater impact in non-permanent $(\mathrm{RR}=4.11$ in men, $\mathrm{RR}=2.98$ in women) than in permanent employees ( $R R=1.80$ in men, $\mathrm{RR}=2.22$ in women). Similarly, stronger associations were found in men non-permanent $(R R=5.20)$ than in permanent employees $(R R=1.24)$ working in passive work.

High control (or low demands) permanent employees were the reference category when assessing the interaction between psychosocial factors and employment status (table 4). Compared with permanent employees with high control, an interesting pattern was seen in non-permanent: high control was associated with lower sickness absence risk, in men $(R R=0.37)$ and women $(R R=0.94)$, but low control was associated with higher risk, in men $(R R=1.63)$ and in women $(R R=1.70)$. Similar results were found for demands in women. Compared with permanent employees with low

Table 4 Risk of work related sickness absence by combined exposure to psychosocial work risk factors and employment status for men and women in a sample of workers $(n=13957)$ from the Third European Survey on Working Conditions (2000)

\begin{tabular}{|c|c|c|c|c|c|}
\hline \multirow[b]{2}{*}{ Variables } & \multicolumn{2}{|c|}{ Permanent } & \multicolumn{2}{|c|}{ Non-permanent } & \multirow{2}{*}{$\begin{array}{l}\text { Test for } \\
\text { interaction* }\end{array}$} \\
\hline & RRa† & $95 \% \mathrm{Cl}$ & RRa† & $95 \% \mathrm{Cl}$ & \\
\hline \multirow{2}{*}{\multicolumn{6}{|c|}{$\begin{array}{l}\text { Men } \\
\text { Psychological job demands } \neq\end{array}$}} \\
\hline & & & & & \\
\hline Low & 1 & - & 0.96 & $(0.66$ to 1.38$)$ & \\
\hline High & 1.27 & (1.12 to 1.44 ) & 1.02 & $(0.74$ to 1.39$)$ & $p=0.455$ \\
\hline \multicolumn{6}{|l|}{ Job controls } \\
\hline High & 1 & - & 0.37 & $(0.20$ to 0.66$)$ & \\
\hline Low & 1.45 & $(1.28$ to 1.63$)$ & 1.63 & (1.25 to 2.14 ) & $p=0.001$ \\
\hline \multirow{2}{*}{\multicolumn{6}{|c|}{$\begin{array}{l}\text { Women } \\
\text { Psychological job demandst }\end{array}$}} \\
\hline & & & & & \\
\hline Low & 1 & - & 0.69 & $(0.49$ to 0.98$)$ & \\
\hline High & 1.19 & (1.04 to 1.37 ) & 1.28 & $(0.97$ to 1.68$)$ & $p=0.047$ \\
\hline \multicolumn{6}{|l|}{ Job controls } \\
\hline High & 1 & & 0.94 & $(0.63$ to 1.39 ) & \\
\hline Low & 1.91 & $(1.67$ to 2.19$)$ & 1.70 & (1.30 to 2.22 ) & $p=0.824$ \\
\hline
\end{tabular}

*Wald test; †adjusted rate ratio for age, marital status, children at home, household chores, country, economic sector, company size, vibrations, fumes, noise, extreme temperatures, carrying load; $¥ 1+$ job control; §1 + job demands. 


\section{Key points}

- Sickness absence is an important measure of the working population's wellbeing and lost productivity.

- The association between psychosocial work factors and work related sickness absence was higher in nonpermanent employees than in permanent employees.

- Men had slightly higher sickness absence than women.

demands, female non-permanent with low demands had lower sickness absence risk $(\mathrm{RR}=0.69)$, but non-permanent with high demands had higher risk $(\mathrm{RR}=1.28)$. Interaction between psychosocial factors and employment status was significant only in men for control and in women for demands.

\section{DISCUSSION}

This study has explored for the first time the association between psychosocial work factors and work related sickness absence by sex taking into account permanent and nonpermanent employees. Specifically, we found: (1) high sickness absence among employees with high psychological demands and low control. Also, high strain work and passive work were positively related to sickness absence; (2) These associations were stronger in non-permanent employees, except for demands in men; (3) Sickness absence was slightly higher in men compared with women and the association with psychosocial work factors was also more pronounced among men; and, (4) potential confounders did not largely modify the results.

The association between psychosocial work factors and sickness absence supports the job strain model and is consistent with previous findings. ${ }^{1-3}{ }^{10-12}$ However, we specifically examined work related sickness absence, which none of the previous studies investigated. In accordance with previous studies, ${ }^{6}{ }^{13}$ we found a stronger association for low control than for high demands. High strain and passive work, both characterised by low control, were positively associated with sickness absence. Our findings underscore the importance of lack of job control in relation to work related sickness absence.

We have examined two comparatively unexplored work types; passive and active work, suggested by the Karasek's model. ${ }^{34}$ Passive work, in male workers, was associated with higher sickness absence compared with low strain. Recently, passive work has been related to increase mortality risk compared with active jobs. ${ }^{35}$ Although our comparison group was different, when active work was used as reference, similar results were obtained (data not shown). Passive work may reflect meaningless work and lack of motivational content, which could lead to high risk behaviours causing health problems that, in turn, may increase sickness absence. ${ }^{35}$ Unfortunately, the ESWC did not contain specific data on this issue. On the other hand, active jobs were negatively related to sickness absence. One previous study found active jobs predict long spells of sickness absence, ${ }^{36}$ but the rural community sample of women $40-50$ years limits comparability with our results. To elucidate the potential multiple links of passive and active jobs with sickness absence is a future challenge.

Consistent with other research, non-permanent employees tend to report less sickness absence than permanent employees. ${ }^{23} 25-27$ We examined whether this relation varied by psychosocial work conditions and gender. Only nonpermanent employees with either low demands or high control had the traditionally observed low risk. Additionally, we found gender differences in sickness absence rates. Only male non-permanent employees working in high control jobs and women non-permanent employees in low demands jobs had lower sickness absence risk. Typically, sickness absence research suggests that the lower non-permanent employee rates are attributable to the insecurity of not being reemployed or lack of benefits, which leads non-permanent employees to remain at work. ${ }^{37-39}$ Furthermore, our research suggests that for female non-permanent employees, high psychological job demands may increase their risk of sickness absence, whereas, for men, having low control or few resources to manage job demands increased sickness absence risk. Clearly, it is important to consider psychosocial work conditions and gender in explaining the impact of employment contracts on sickness absence.

Prudence is needed when generalising our findings to all types of non-permanent employees. The non-permanent employees form a heterogeneous population, within which working conditions and ill health may vary. ${ }^{40}$ It would be useful to distinguish between non-permanent employees who have freely chosen this type of employment-as a complementary to other tasks they do such as studying or taking care of somebody at home-and those working in an undesirable non-permanent situation. Involuntary and voluntary employees are likely to differ in their work motivation. ${ }^{41}$ Involuntary employees would be more concerned about gaining a secure future employment than voluntary, which could influence their decision to take sick leave.

The job strain model does not use job security in constructing work stress, but the effort-reward imbalance (ERI) does. The ERI model considers job stability as a type of social reward that workers expect for their work effort. Very little research exists with sickness absence as an outcome using the ERI model. ${ }^{42}$ One study showed workers in a low demand job with poor rewards, defined as job insecurity, engaged in with passive (that is, sickness absence behaviour) rather than active coping (that is, internalisation of stress). Non-permanent status may be an indicator of job insecurity in our research. Interestingly, our results showed that male non-permanent workers in passive work have the higher sickness absence risk than workers in the three other work states defined by the demand-control model. The idea of passive coping depicted by Peter and Siegrist represents a similar disengagement for passive work. ${ }^{34}$ Alienation and disengagement from work and society related to work depleted of meaningful content, defined by the passive work state, can be manifested. Future research would benefit from theoretical and empirical work considering the joint application of these work stress models to non-permanent work.

Association of psychosocial factors and sickness absence by employment was more pronounced among men as compared with women, and in contrast with expected, sickness absence tended to be slightly higher in men. Gender differences in sickness absence have been attributed to both the unequal

\section{Policy implications}

- Public policies aimed at reducing health inequalities and increasing labour rights equity between types of employment and sex should be considered.

- With regard to non-permanent employees, business and healthcare professionals should especially pay attention to the increased risk of lost productivity related to health and lack of control at work. 
distribution of working conditions ${ }^{43}{ }^{44}$ and family demands. ${ }^{45}$ Firstly, division of labour by gender might be diluted when a heterogeneous working population such as ours is analysed. Secondly, most studies 283646 did not control for family demands as we did. Moreover, unlike other studies, we specifically measured work related sickness absence whereas usually all cause sickness absence is used.

One study limitation is that sickness absence data were self reported and measured retrospectively for the previous year, which may introduce biases. ${ }^{47}$ Despite concerns about the exclusive use of self reported sickness absence, ${ }^{48}$ the main practical reason to use it is the unfeasibility to get registries from each employee's workplace in large public samples such as ours. ${ }^{49}$ However, self reported data have some advantages, as declaration instead of registry could make sickness absence less conditioned by practices and regulations of each setting. ${ }^{49}$ For example, lately it has been noted that medical experts could underestimate the work related attribution of health problems as compared with employees. ${ }^{50}$

In addition, two opposed effects might be considered when using self reports. Firstly, an overestimation of the relation between psychosocial factors and sickness absence could exist because working conditions can affect not only the generation of employees' ill health and sick leave taking, but also their return to work by means of the perception about the cause of the absence. ${ }^{19}$ Secondly, social desirability processes are likely to underestimate the associations making people reluctant to admit being sick because of work strain.

A healthy worker effect might be present as employees with unusual working time schedule or worse health level (that is, a long term disability state) would have not being available for the interview. This potential bias would underestimate the associations as selected employees would be healthier, and possibly had less sickness absence than nonselected employees. In addition, our study relies on cross sectional data so we cannot to rule out the possibility of reverse causality (that is, sickness absence would modify psychosocial work factors). Another concern is the low response rate in countries such as Greece $(47 \%)$, Denmark $(42 \%)$, the Netherlands (41\%), and Italy (39\%). This could be a major issue in country specific or between country analyses, but we are analysing the whole EU sample and thus the potential bias is less severe.

Finally, from a methodological perspective, the questions used to measure the psychosocial work environment were non-standard. Good internal consistency was found for the job control scale $(\alpha=0.75)$ but for job demands the $\alpha$ was low $(\alpha=0.53)$. All selected items measured similar constructs contained in the standard scales. ${ }^{51}$ However, the small number of job demands items captured only work intensity and not the full conceptual demands range. This could explain the lower than expected reliability.

In summary, psychosocial work risk factors in nonpermanent employees, particularly low control, were more strongly associated to work related sickness absence than in their permanent employed counterparts, and more so in men than in women. Several implications can be drawn from our findings. From a research point of view, the findings support the need to investigate permanent and non-permanent employees separately. Our results suggest the need to develop public policies given the complex reality of how the workplace environment and psychosocial factors are interrelated. Changes in EU legislation and preventive actions aimed at reducing employment and gender inequalities should be considered.

\section{ACKNOWLEDGEMENTS}

We thank Marcelo Amable from the Occupational Health Research Unit from the Universitat Pompeu Fabra for his valuable comments.

\section{Authors' affiliations}

D Gimeno, F G Benavides, J Benach, J M Martínez, Occupational Health Research Unit, Department of Experimental Sciences and Health, Universitat Pompeu Fabra, Barcelona, Spain

D Gimeno, B C Amick III, School of Public Health, University of TexasHouston Health Science Center, Houston, USA

B C Amick III, Texas Program for Society and Health, Rice University, Houston, USA

B C Amick III, Institute for Work and Health, Toronto, Canada

Funding: this work was partly funded by the European Foundation for the Improvement of Living and Working Conditions (Project 0156/ contract 00-3030-85).

Conflicts of interest: none declared.

\section{REFERENCES}

1 Marmot M, Feeney A, Shipley $M$, et al. Sickness absence as a measure of health status and functioning: from the UK Whitehall II study. J Epidemiol Community Health 1995:49:124-30.

2 Bourbonnais $\mathbf{R}$, Vinet $A$, Vezina $M$, et al. Certified sick leave as a non-specific morbidity indicator: a case-referent study among nurses. $\mathrm{Br} J$ Ind Med 1992;49:673-8.

3 Gründemann RWM, van Vuuren CV. Preventing absenteeism at the workplace. Dublin: European Foundation for the Improvement of Living and Working Conditions, 1997:43-4.

4 Karasek RA. Job demands, job decision latitude, and mental strain: implication for job redesign. Administrative Science Quarterly 1979;24:285-308.

5 Van Yperen NW, Snijders TA. A multilevel analysis of the demands-control model: is stress at work determined by factors at the group level or the individual level? J Occup Health Psychol 2000;5:182-90.

6 Karasek R, Gardell B, Lindell J. Work and non-work correlates of illness and behaviour in male and female Swedish white collar workers. J Occup Behav 1987:8:187-207.

7 North FM, Syme SL, Feeney A, et al. Psychosocial work environment and sickness absence among British civil servants: the Whitehall II study. Am J Public Health 1996;86:332-40

8 Niedhammer I, Bugel I, Goldberg M, et al. Psychosocial factors at work and sickness absence in the Gazel cohort: a prospective study. Occup Environ Med 1998;55:735-41

9 Kivimäki M, Vahtera J, Pentti J, et al. Factors underlying the effect of organisational downsizing on health of employees: longitudinal cohort study. BMJ 2000;320:971-5

10 Vahtera J, Kivimäki M, Pentti J, et al. Effect of change in the psychosocial work environment on sickness absence: a seven year follow up of initially healthy employees. J Epidemiol Community Health 2000;54:484-93.

11 Ala-Mursula L, Vahtera J, Kivimäki $M$, et al. Employee control over working times: associations with subjective health and sickness absences. J Epidemiol Community Health 2002;56:272-8.

12 Dwyer DJ, Ganster DC. The effects of job demands and control on employee attendance and satisfaction. J Organiz Behav 1991;12:595-608.

13 Kristensen TS. Sickness absence and work strain among Danish slaughterhouse workers: an analysis of absence from work regarded as coping behaviour. Soc Sci Med 1991;32:15-27.

14 Bourbonnais R, Mondor M. Job strain and sickness absence among nurses in the province of Quebec. Am J Ind Med 2001;39:194-202.

15 de Jonge J, Reuvers MM, Houtman IL, et al. Linear and nonlinear relations between psychosocial job characteristics, subjective outcomes, and sickness absence: baseline results from SMASH. Study on Musculoskeletal Disorders, Absenteeism, Stress, and Health. J Occup Health Psychol 2000;5:256-68.

16 Voss M, Floderus B, Diderichsen F. Physical, psychosocial, and organisational factors relative to sickness absence: a study based on Sweden Post. Occup Environ Med 2001;58:178-84

17 de Lange AH, Taris TW, Kompier MA, et al. Effects of stable and changing demand-control histories on workers health. Scand J Work Environ Health 2002;28:94-108.

18 Benavides FG, Benach J, Mira M, et al. Occupational categories and sickness absence certified as attributable to common diseases. Eur J Public Health 2003;13:51-5.

19 Benavides FG, Benach J, Moncada S. Working conditions and sickness absence: a complex relation. J Epidemiol Community Health 2001;55:368.

20 Whitaker SC. The management of sickness absence. Occup Environ Med 2001;58:420-4.

21 Benach J, Muntaner C, Benavides FG, et al. A new occupational health agenda for a new work environment. Scand J Work Environ Health 2002;28:191-6.

22 Letourneux V. Precarious employment and working conditions in European Union. Luxembourg: Office for Official Publications of the European Communities, 1998

23 Benavides FG, Benach J, Diez-Roux AV, et al. How do types of employment relate to health indicators? Findings from the second European survey on working conditions. J Epidemiol Community Health 2000;54:494-501.

24 Kivimäki M, Vahtera J, Virtanen $M$, et al. Temporary employment and risk of overall and cause-specific mortality. Am J Epidemiol 2003;158:663-8.

25 Benach J, Gimeno D, Benavides FG, et al. Types of employment and health in the European Union: changes from 1995 to 2000. Eur J Public Health 2004;14:314-21. 
26 Virtanen $\mathbf{P}$, Vahtera J, Kivimäki $M$, et al. Employment security and health. J Epidemiol Community Health 2002;56:569-74.

27 Virtanen $M$, Kivimäki $M$, Elovainio $M$, et al. Contingent employment, health and sickness absence. Scand J Work Environ Health 2001 :27:365-72.

28 Moncada S, Navarro A, Cortés I, et al. Sickness leave, administrative category and gender: results from the "Casa Gran" project. Scand J Public Health 2002;(suppl 59):26-33.

29 Paoli P, Merllié D. Third European Survey on working conditions 2000 Luxembourg: Office for Official Publications of the European Communities, 2001.

30 Theorell T, Karasek RA. Current issues relating to psychosocial job strain and cardiovascular disease research. J Occup Health Psychol 1996;1:9-26.

31 McCullagh P, Nelder JA. Generalized linear models. 2nd ed. London: Chapman and Hall, 1989.

32 Szklo M, Nieto FJ. Epidemiology, beyond the basics. Gaithersburg: Aspen, 2000.

33 Hosmer DW, Lemeshow S. Applied logistic regression. 2nd ed. New York: Wiley, 2000.

34 Karasek R, Theorell T. Healthy work. Stress, productivity, and the reconstruction of working life. New York: Basic Books, 1990.

35 Amick BC 3rd, McDonough P, Chang $\mathrm{H}$, et al. elationship between all-cause mortality and cumulative working life course psychosocial and physical exposures in the United States labor market from 1968 to 1992. Psychosom Med 2002;64:370-81.

36 Krantz G, Östergren P-O. Do common instance symptoms in women predict long spells of sickness absence? A community-based study on Swedish women 40 to 50 years of age. Scand J Public Health 2002;30:176-83.

37 Smulders PGW, Nijhuis FJN. The job demand-job control model and absence behaviour: results of a 3-year longitudinal study. Work Stress 1999;13:115-31.

38 Virtanen $M$, Kivimäki $M$, Elovainio $M$, et al. Selection from fixed term to permanent employment: prospective study on health, job satisfaction, and behavioural risks. J Epidemiol Community Health 2002;56:693-9.

39 Aronsson G, Gustafsson K, Dallner M. Sick but yet at work. An empirical study of sickness presenteeism. J Epidemiol Community Health 2000;54:502-9.
40 Aronsson G, Gustafsson K, Dallner M. Work environment and health in different types of temporary jobs. Eur J Work Org Psychol 2002;1 1:151-5.

41 Von Hippe C, Greengerger DB, Heneman RL, et al. Voluntary and involuntary temporary employees: predicting satisfaction, commitment and personal control. Research in the Sociology of Work 2000;9:291-309.

42 Peter R, Siegrist J. Chronic work stress, sickness absence, and hypertension in middle managers: general or specific sociological explanations. Soc Sci Med 1997;45: $1111-20$.

43 Messing K, Tissot F, Saurel-Cubizolles MJ, et al. Sex as a variable can be a surrogate for some working conditions: factors associated with sickness absence. J Occup Environ Med 1998;40:250-60.

44 Feeney A, North F, Head J, et al. Socioeconomic and sex differentials in reason for sickness absence from the Whitehall II Study. Occup Environ Med 1998:55:91-8.

45 Artazcoz L, Borrell C, Benach J. Gender inequalities in health among workers: the relation with family demands. J Epidemiol Community Health 2001;55:639-47.

46 Blank N, Diderichsen F. Short-term and long-term sick-leave in Sweden: relationships with social circumstances, working conditions and gender. Scand J Soc Med 1995;23:265-72.

47 Checkoway H, Pearce N, Crawford-Brown DJ. Research methods in occupational epidemiology. New York: Oxford University Press, 1989

48 Frese M, Zapf D. Methodological issues in the study of work stress: objective vs subjective measurement of work stress and the question of longitudinal studies. In: Cooper CL, Payne R, eds. Causes, coping and consequences of stress at work. Chichester: Wiley, 1988

49 Johns G. How often are you absent? A review of the use of self-reported absence data. J Appl Psychol 1994;79:574-91.

50 Castejón J, Jarque S, Benach J, et al. El papel de las condiciones de trabajo en la incidencia de la incapacidad temporal por contingencias comunes. Resultados de un estudio piloto. [The potential occupational origin of short non-occupational sick-leave spells. Findings from a pilot study]. Arch Prev Riesgos Labor 2000;3:12-17.

51 Karasek R, Brisson C, Kawakami N, et al. The Job Content Questionnaire (JCQ): an instrument for internationally comparative assessments of psychosocial job characteristics. J Occup Health Psychol 1998;3:322-55. 